\title{
MSAS Frequency Score Likert Scale
}

National Cancer Institute

\section{Source}

National Cancer Institute. MSAS Frequency Score Likert Scale. NCI Thesaurus. Code C134966.

A scale for the subjective scoring of event frequency that ranges from 1: Almost Never to 4: Almost Always designed for use with the Memorial Symptom Assessment Scale (MSAS) 10-18. 